\title{
NOTES ON THE INHERITANCE OF VARIATIONS IN THE COLOR PATTERN OF CRIOCERIS ASPARAGI. ${ }^{1}$
}

BY FRANK E. LUTZ, COLD SPRING HARBOR, N. Y.

Crioceris asparagi is the ordinary asparagus beetle. Both males and females hibernate as adults in the stalks of dead plants - chiefly asparagus. They emerge about the middle of May, and eggs are laid in a few days. These hatch in 2 to 4 days. The larvæ feed on the asparagus for from 1 to 3 weeks and then go into the ground to pupate. The pupal stage is from 4 to 10 days in duration. The maximum number of offspring I was able to rear from a single pair was 57. Copulation is repeated and frequent. There seem to be, normally, two generations a season, although a few of a third generation can be procured. It is comparatively easy to keep the adults over winter in glass vials loosely stuffed with paper.

In doing pedigree work with Crioceris much time can be saved by growing asparagus seedlings where beetles can not get at them. Otherwise, one must look over the "leaves" of the food plant very carefully to guard against the introduction of wild eggs or larvæ. If a branch of asparagus be put in a vial with a gravid female she will lay freely upon it and the larvæ may be fed in the vial by supplying fresh food daily. When full grown, they will pupate in the vial even without earth to go into. However, I found the following plan much easier. Asparagus seedlings were grown in pots. Then a lamp chimney was put over the seedlings and partly sunk into the earth. The top was covered with netting. Into this the mated pair was put. After ten or a dozen eggs were laid the pair was transferred to another similar cage. The larvæ which hatched fed on the growing seedlings and when full grown went into the earth to pupate. By that time most of the asparagus had been consumed, so that when the beetles emerged they could easily be seen and removed for recording and mating.

The elytra of Crioceris are blue-black in ground color with a reddish anterior and distal border. There are three yellow areas or "spots" on each elytron. These spots are frequently united in various ways giving quite a range of variation in color pattern. The character whose inheritance was studied was the joining of the anterior

1 A study of the inheritance of variations in the color pattern of this beetle was started several years ago, but owing.to the press of other work there is little likelihood of the present writer's completing it in the near future. These notes are submitted in the hope that some one may take up and solve the several important problems which are involved. The cut is kindly loaned by The Carnegie Institution of Washington. 
and middle spots. It will be seen in the figure that the gradation from $a$ to $e$ is perfect, the melanic pigment disappearing last (or coming in first, according to the view-point) from a small dot in the centre of the band of union. Furthermore, the two elytra of a single insect occasionally show the two extremes of this range and the intermediate combinations are common. This phenomenon is not illustrated in the figure. At first sight this is hopeless from a Mendelian standpoint. It was found, however, that "spots united" is, within limits, recessive to "spots distinct" in the Mendelian sense.

A female of pattern $a$, mated with a male $c$ on the left elytron and $e$ on the right $(\mathrm{DD} \times \mathrm{RR})$ gave 37 offspring only one of which had any sign of union of the spots. The latter had the spots distinct on one elytron and only slightly joined on the other. Another similar mating gave 42 in 47 offspring with no sign of union of the spots. The remaining 5 had a very slight joining on one elytron. A female having $e$ on the right and $b$ on the left by a male $b$ on the right and $c$ on the left $(\mathrm{RR} \times \mathrm{RR}$ but with

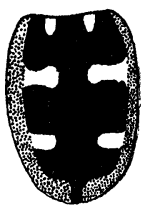

$a$

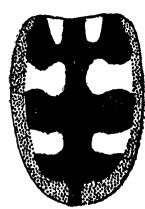

b

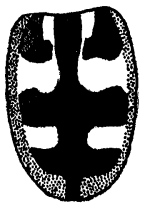

c

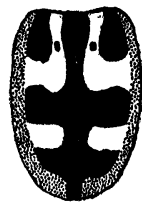

$d$

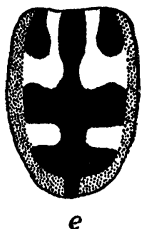

e

Variation in the Color Pattern of Crioceris asparagi.

the recessive characteristic only slightly developed) gave 16 offspring all but one of which had the spots more or less united. Eight matings of spots united $\times$ spots united gave 132 offspring of which only 3 had the spots distinct. Four matings of $\mathrm{DR} \times \mathrm{DR}$ were obtained. The result was spots distinct : spots united : :11:6, $22: 9,34: 13$, and $15: 7$, or a total of $82: 35$. Three matings of $\mathrm{DR} \times \mathrm{RR}$ gave spots distinct : spots united : : 8:8, $3: 3$, and $13: 12$, or a total of $24: 23$. These results are surprisingly close to Mendelian expectation. Ten matings of $a \times a$ (DD $\times$ DD) gave 285 offspring only 6 of which had the spots at all joined.

Thus we have here a good case of a perfectly graded variation obeying rather closely the Mendelian law. Spots joined, even slightly and on one elytron only, marks a "pure" recessive individual. However there are variations in the relative potencies of the allelomorphs such as have been found in the cases of height or nostrils in chickens, abnormal wing veins in Drosophila and other characters. Some of the interesting problems suggested are: (1) Is pattern $c$, for example, dominant over 
pattern $e$ - both in the recessive group? (2) Pattern $b$ seems to be characteristic of the DR's. In how far is this so? (3) Specimens occur in which the middle spot is joined to the posterior one. How does this character behave in inheritance? (4) Specimens having all the spots joined are more common near Washington, D. C., than near New York. Is there a definite geographic variation, melanism increasing toward the North? (5) How is the color pattern affected by experimentally modified environment? 

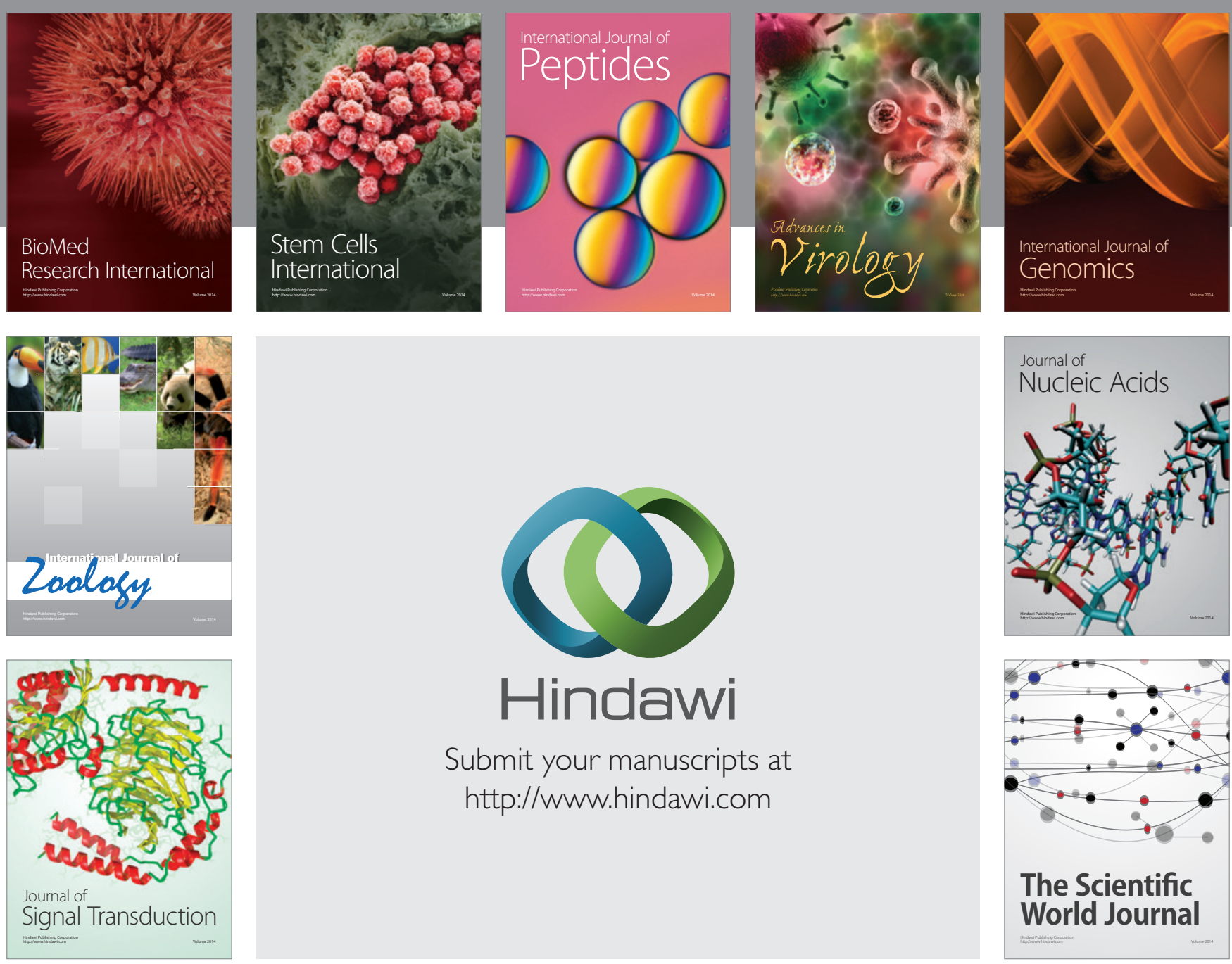

Submit your manuscripts at

http://www.hindawi.com
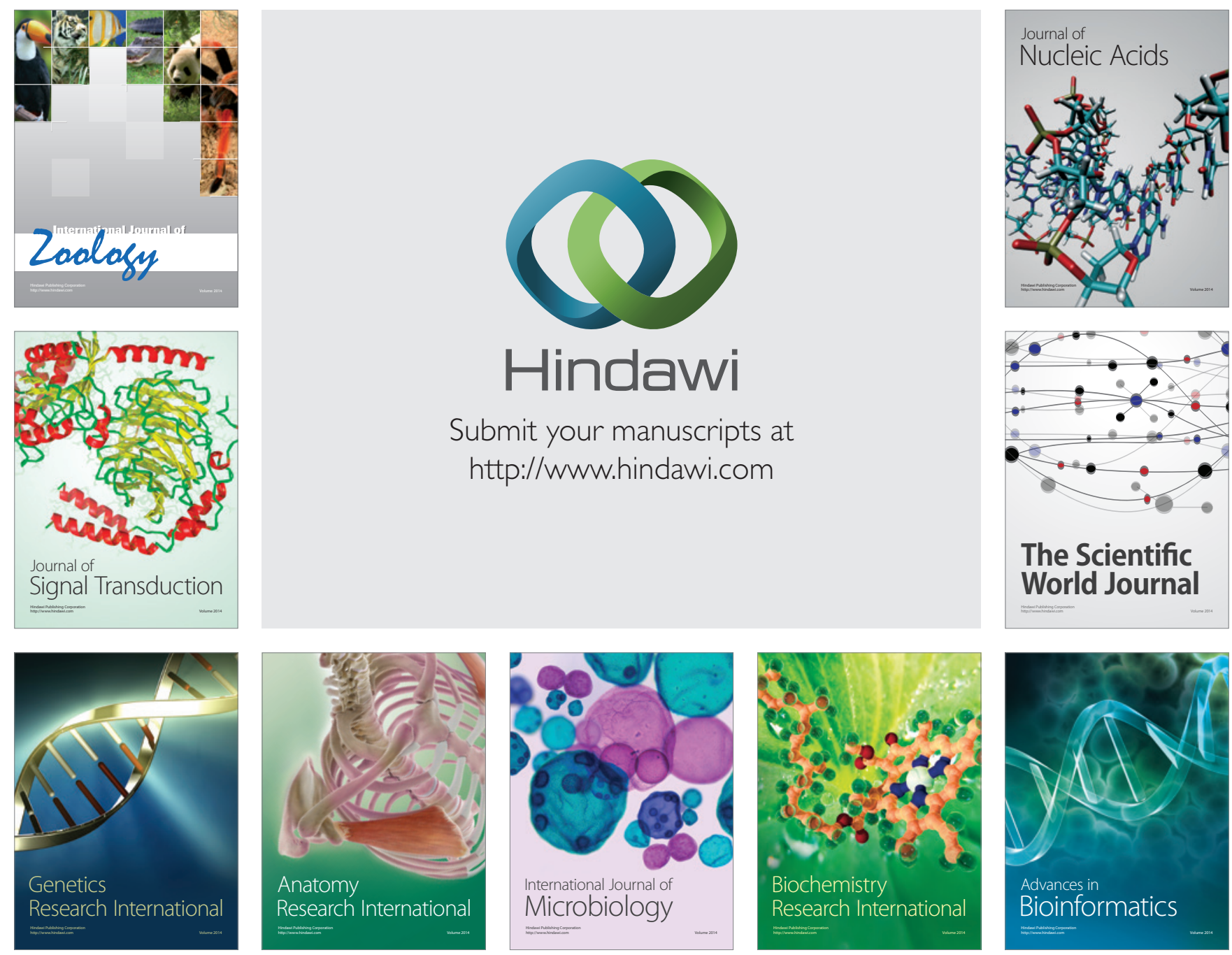

The Scientific World Journal
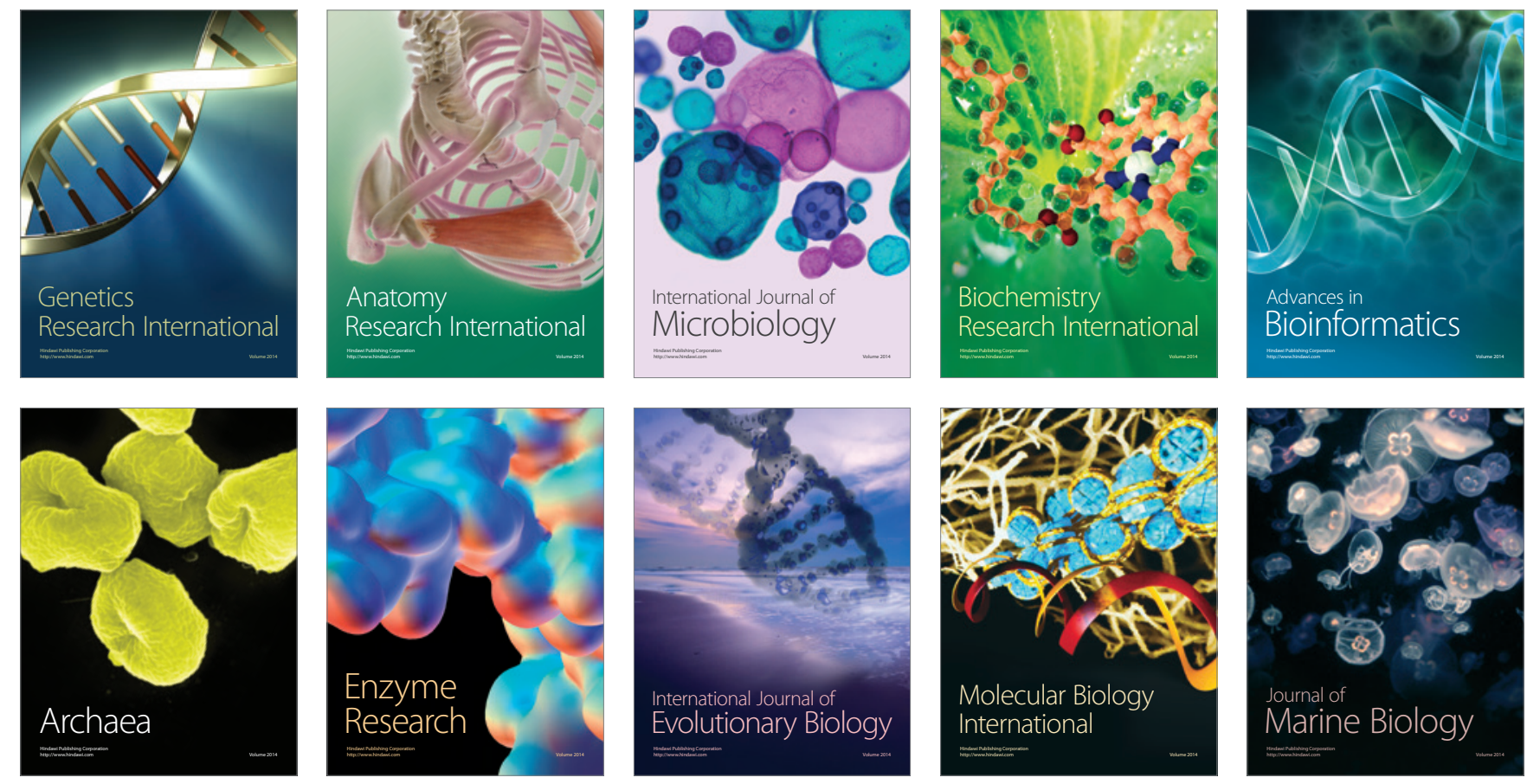